\title{
The origin and bloating of the obsidian
}

\author{
Artsruni Safaryan ${ }^{1}$, Tamara Sarkisyan ${ }^{1}$, Tatevik Paytyan ${ }^{1 *}$ and Armine Baghdagyulyan ${ }^{1}$ \\ ${ }^{1}$ National University of Architecture and Construction of Armenia, 105 Teryan Street, Yerevan, \\ Republic of Armenia
}

\begin{abstract}
Among the rocks used to produce heat-insulating and acoustic building materials, volcanic water-containing glassy rocks are increasingly being used. A feature of volcanic water-containing glasses is their ability to expand during heat treatment. Besides perlite, other volcanic glasses known by various names also have this special feature: obsidian, pitchstone, vitrophire, and others. The common property of all these rocks, which determines their expanding power, is the content of water in them, being in various forms of linkage. The main role in the process of their pore formation during bloating belongs to water and various gases located in closed pores. Obsidian is expanded at temperatures of $1050 \ldots 11500 \mathrm{C}$. The lowest average density of $200 \ldots 350 \mathrm{~kg} / \mathrm{m} 3$ (in a piece) is obtained by heat treatment of obsidian for $3 \ldots 10$ minutes (depending on the size of the sample).
\end{abstract}

\section{Intduction}

Rock formation is associated with the eruption of molten magma and rapid cooling. The composition and temperature of the lava and the cooling rate are crucial for the occurrence of volcanic glass. Stone is formed when molten rocks do not have time to crystallize due to rapid cooling. Most of the known deposits originated in the Pliocene period 2-4 million years ago. Obsidian finds are no older than the Cenozoic era (new life), which has been going on for 65 million years [1-4].

Since obsidian is the result of volcanic activity and lava eruptions, it is formed in nature where there are active volcanoes, dormant or extinct. Therefore, the scope of its distribution is quite wide.

The mineral was first discovered 9,000 years ago in Mesopotamia.

Large deposits of this stone are found in countries with high volcano activity, such as Mexico, Ecuador, Japan (Hokkaido island), Turkey, and Armenia.

Mexico has the largest deposits of obsidian, and there are rare species of it - red and brown-red.

In Russia, the mineral is extracted in the regions of Kamchatka and the Kuril Islands, the Caucasus, Karelia, and Siberia. Minor deposits of obsidian are present in the TransBaikal and the Khabarovsk regions.

In addition, the stone is found in other countries and regions, too: in Peru and Iceland, Hawaii and Indonesia. Large deposits are located in Iran and Georgia.

\footnotetext{
* Coresponding author: paytyantatevik@gmail.com
} 
The oldest deposits of obsidian were discovered in ancient times in Anatolia: one - in the valley of the Konya River, the other - near the Lake Van. In Armenian, obsidian is called "vanakat" (Van's milk) [5].

There are many colours of obsidian: black, grey, brown, pearl, "Apache's tear", as well as striped, obsidian and perlite (Fig. 1).

The name of this stone only increases its mystery. Obsidian is also called "devil's claw", "Apache's tear", and bottle stone. There are different versions of the origin of this stone's name.

The adherents of the first version suggest that it comes from the word "obsis", which is translated from Greek as "spectacle". Perhaps this name arose from the fact that in ancient times mirrors were made of obsidian (Fig. 1).

According to the second version, the stone is named after the Roman Obsius or Obsidius, who first brought this stone to Italy from Africa (Ethiopia) [6].
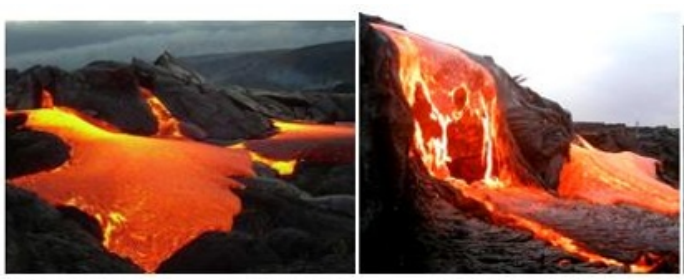

a)

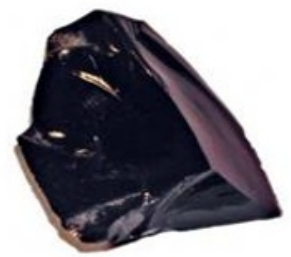

b)

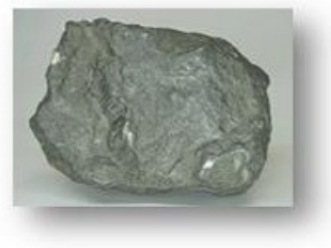

c)

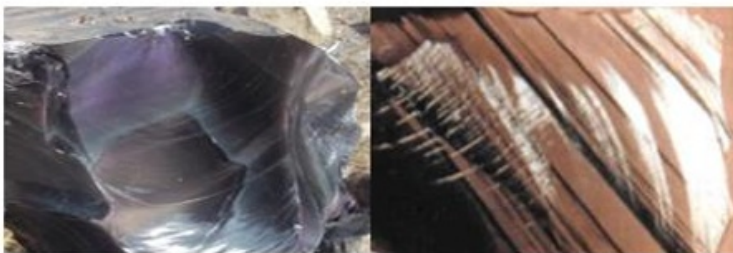

e)

f)

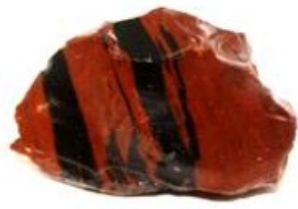

h)

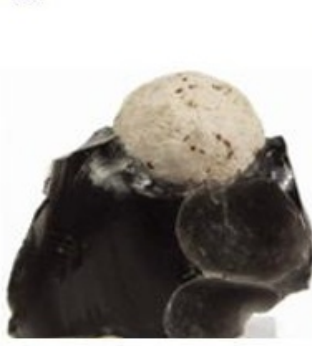

i)
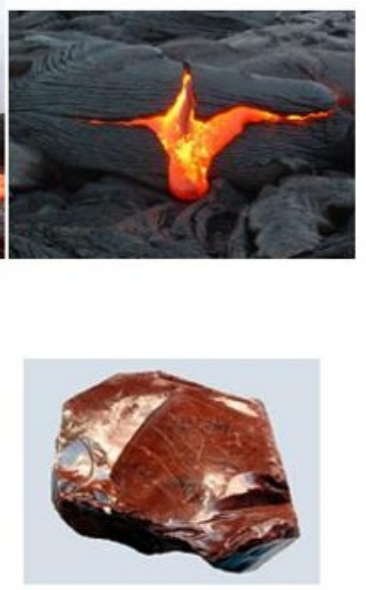

d)

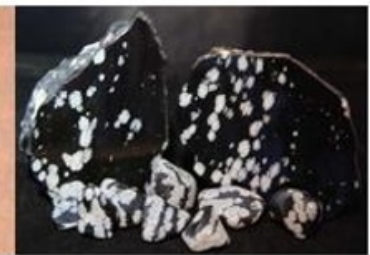

g)



j)

Fig. 1 a) Obsidian lava; varieties of obsidian: b) black, c) grey, d) brown, e) pearl, f) a chip of obsidian g) "Apache's tear", h) striped, i) obsidian and perlite, j) a mirror of obsidian 
The chemical composition of the mineral includes the following elements: $\mathrm{SiO}_{2}$ (silicon oxide) is its base, the content of which ranges from $65 \%$ to $80 \%$; water is contained in very small amounts - up to $1 \%$.

Obsidians of different deposits feature relatively close chemical compositions in which the content of oxides varies within the following limits (\% of the mass): $\mathrm{SiO}_{2}$ $65,01 \ldots 79,42 ; \mathrm{Al}_{2} \mathrm{O}_{3}-6,6 \ldots 16,32 ; \mathrm{Fe}_{2} \mathrm{O}_{3}-0,09 \ldots 1,9 ; \mathrm{CaO}$ traces - 2,63; $\mathrm{MgO}-$ $0,01 \ldots 1,3 ; \mathrm{SO}_{3}-0 \ldots 0,41 ; \mathrm{NaO}+\mathrm{K}_{2} \mathrm{O}-2,02 \ldots 9,81$; the filament loss $-0,14 \ldots 0,4$. The characteristics of their physical properties include the following parameters: hardness about 5 to 5,5 (on the Mohs scale); density - from 2,5 to 2,6 $\mathrm{g} / \mathrm{m}^{3}$ [7,8].

The black color of obsidian is often caused by powdery inclusions of magnetite, while hematite gives the stone a reddish-brown tone. The location of the stripes indicates the direction of the lava flow [1-4].

The structure of the stone is massive amorphous with a uniform texture, and the strength is low. The mineral has no electrical conductivity, is not radioactive, and melts at a temperature of 1200 to 1500 degrees Celsius. It can be opaque, translucent, or transparent. It has a glass lustre, it is polishable and can be cut.

In industry, the mineral is used as a raw material for producing dark-colored glass. And for construction, it is used to produce a heat-insulating material [7, 8].

A common property for bloated rocks is the ability to significantly increase the volume of rock grains due to intensive withdrawal of bound water from them during hightemperature processing. Swelling of pre-crushed rock occurs when it acquires a ductileviscous (pyroplastic) state when heated, and the main role in the process of pore formation during bloating belongs to water and various gases located in closed pores [7, 8].

\section{Methodology}

The suitability of raw materials for expanding is determined by the degree of its bloating during heat treatment and the average density (bulk and in a piece).

At ignition of the raw material, the mass loss should not exceed $3.0 \%$, and the bloating interval of the raw material should be at least $50^{\circ} \mathrm{C}$. The bloating interval is the interval between the temperature at which the expanded material with the lowest average density in the piece is obtained, and the temperature at which the surface of the obsidian grains begins to melt.

The locations of obsidian in Armenia are: Aragats, Artenis, Gyumush-Jraber, JraberFontan, Vorotan, Kecheldag (upper reaches of the Terter river, Kelbajar district, NKR). The chemical composition of obsidians of different colors is shown in the table below.

Table 1. Chemical composition of obsidians of different colours from the Jraberd deposits, mas. \%.

\begin{tabular}{|l|c|c|c|c|c|c|c|c|}
\hline $\begin{array}{c}\text { Color of } \\
\text { the sample }\end{array}$ & $\mathrm{SiO}_{2}$ & $\mathrm{Al}_{2} \mathrm{O}_{3}$ & $\begin{array}{c}\mathrm{Fe}_{2} \mathrm{O}_{3}, \\
\text { recalculated }\end{array}$ & $\mathrm{CaO}$ & $\mathrm{MgO}$ & $\mathrm{SO}_{3}$ & $\mathrm{NaO}+\mathrm{K}_{2} \mathrm{O}$ & LOI \\
\hline Grey & 73,60 & 14,53 & 0,69 & 1,20 & 0,25 & 0,31 & 8,92 & 0,41 \\
\hline Black & 74,46 & 14,20 & 1,12 & 1,25 & 0,28 & 0,14 & 8,23 & 0,32 \\
\hline Brown & 76,96 & 13,33 & 0,96 & 1,19 & 0,22 & 0,16 & 6,97 & 0,21 \\
\hline
\end{tabular}




\section{Results}

In Fig. 2, the results of mass loss of obsidian samples of different colours at different temperatures are presented. From the results obtained, it follows that the greatest losses are in the grey sample, i.e. its bloating power is higher.

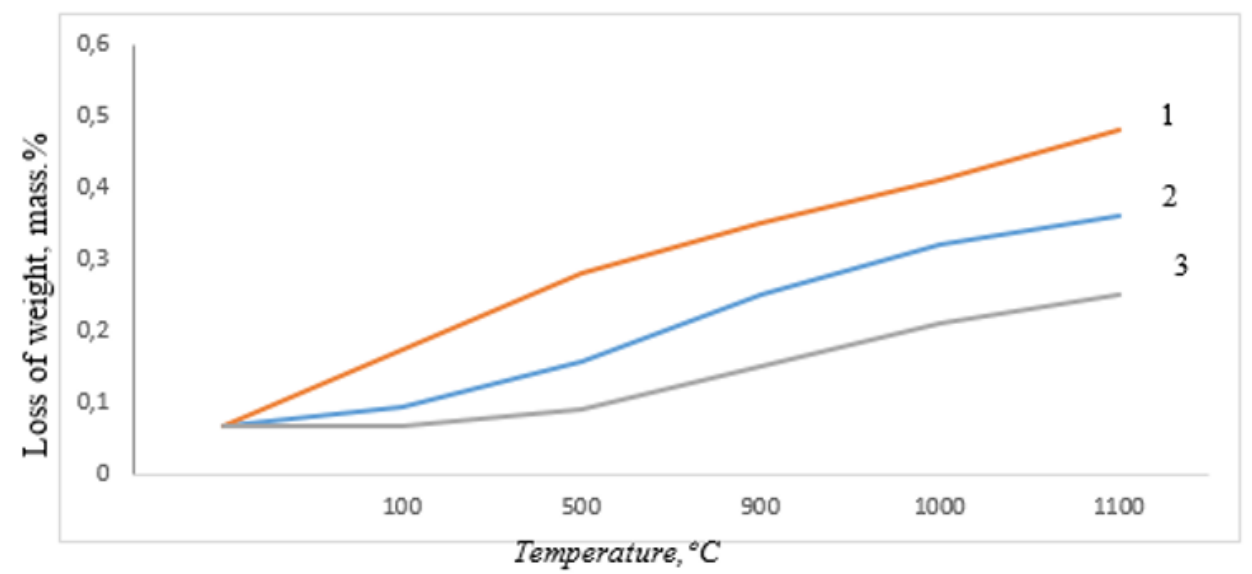

Fig. 2. Loss of mass of the obsidian sample of different colours at different temperatures: 1 - black obsidian, 2 - grey obsidian, 3 - brown obsidian.

The density of the grey samples is $2310 \mathrm{~kg} / \mathrm{m}^{3}$, the black samples $-2400 \mathrm{~kg} / \mathrm{m}^{3}$, and the brown samples $-2550 \mathrm{~kg} / \mathrm{m}^{3}$. The average densities are $2250 \mathrm{~kg} / \mathrm{m}^{3}, 2380 \mathrm{~kg} / \mathrm{m}^{3}, 2490$ $\mathrm{kg} / \mathrm{m}^{3}$ respectively. The average density of the boated grey sample was $200 \mathrm{~kg} / \mathrm{m}^{3}$, black sample - $350 \mathrm{~kg} / \mathrm{m}^{3}$, and the brown sample $-950 \mathrm{~kg} / \mathrm{m}^{3}$ (in pieces). Obsidian is expanded at temperatures of $1050 \ldots 1150^{\circ} \mathrm{C}$. The lowest average density of $200 \ldots 350 \mathrm{~kg} / \mathrm{m}^{3}$ (in a piece) is obtained by heat treatment of obsidian for $3 \ldots 10$ minutes (depending on the size of the sample).

Fig. 3 shows photos of the original non-bloated obsidian, the bloated obsidian, and the porosity of the bloated obsidian.

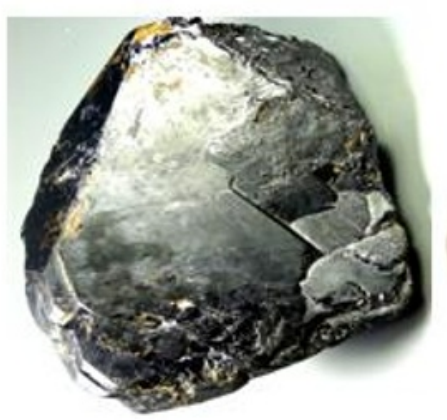

a)

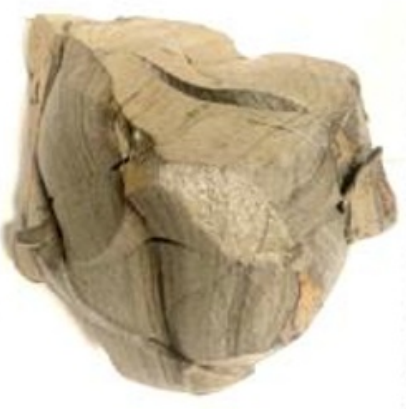

b)

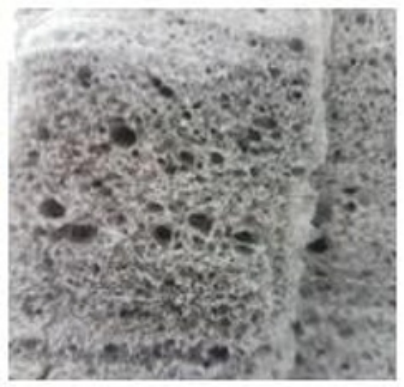

c)

Fig. 3. a) Original non-bloated obsidian, b) bloated obsidian, c) porosity of the bloated obsidian. 


\section{Conclusion}

Gases that expand in the heated mass of glass (water vapor, $\mathrm{CO}_{2}$, etc.) cause high pressure, thus overcoming the forces of adhesion of particles (depending on the viscosity of the mass) and make the material swell.

The bloated obsidian will allow you to obtain an ultra-light large-porous material. On the basis of expanded obsidian, it is possible to obtain new types of effective composite thermal insulation and acoustic materials (light and cellular concrete, monolithic products and acoustic plasters) with high performance properties and expand the range of effective construction composite materials.

\section{References}

1. Perlite and vermiculite (Geology, exploration technique and technology) // Digest of articles (Gosgeoltekhizdat, Moscow, 1962)

2. S.P. Komenetsky, Perlites (All-Union Scientific Research and Design Institute Teploproekt, Moscow, 1963)

3. V.V. Nasedkin, V.P. Petrov, Perlites // Collection of articles of the Academy of Sciences of the USSR (Pub. Science, Moscow, 1981)

4. V.V. Nasedkin, Petrogenesis of acidic volcanics (Nauka, Moscow, 1975)

5. K.M. Saghatelyan, Perlites of Armenia (Gosgeolizdat, Moscow, 1962)

6. B.F. Kulikov B. F. Dictionary of gem stones (Nedra, Leningrad, 1988)

7. A.I. Augustnik, Physical chemistry of silicates (Stroyizdat, Moscow, 1966)

8. Yu.P. Gorlov, Technology of heat-insulating and acoustic materials and products (Higher school, Moscow, 1989) 